\title{
SOCIO-PERSONAL CORRELATES OF PARTICIPATION IN LIVELIHOOD ACTIVITIES AMONG RURAL YOUTH IN J ABALPUR DISTRICT OF MADHYA PRADESH, INDIA
}

\author{
V.C. Umunnakwe ${ }^{*}$ and F.O. Olajide-Adedamola ${ }^{2}$
}

Received 23 March 2015, Revised 18 May 2015, Accepted 26 June 2015, Published online 30 June 2015

\begin{abstract}
The increasing realization of the negative political, social and economic consequences stemming from the precariousness of youth's livelihoods, underscores the need to understand their livelihood activities, which is a requisite for curbing social ills and reducing rural poverty. The paper examined the participation of rural youth in livelihood activities, their socio-personal characteristics, the relationship between their socio-personal characteristics and their participation in livelihood activities as well as the interrelationships among their socio-personal characteristics. Multi-stage random sampling was used to collect data from 247 respondents through interview schedule. Frequency counts and percentages were used to present data while Pearson product moment correction (PPMC) was used to test relationships. The results revealed that majority of the respondents were from other backward caste (66\%), married (72.10\%), belonged to joint (57.90\%) and medium (50.60\%) size families as well as families that were self-employed in agriculture (59.50\%). Higher percentages of the respondents and their fathers were educated up to higher school and above. Huge majority (75.71\%) of the respondents participated in cereal production while more than half of the respondents were involved in pulse production (56.28\%) and petty trading (53.44\%). Marital status; fathers' educational attainment; family type and family size had significant relationship with participation in livelihood activities. Inter-correlations among socio-personal characteristics showed that caste was related to marital status and educational attainment. It is concluded that socio-personal attributes of rural youth are related to their participation in livelihood activities. The study recommends that socio-personal variables of present study be considered by rural development policy makers when undertaking programmes aimed at enhancing rural youth's livelihoods.
\end{abstract}

Keywords: Rural Youth, Livelihood, Socio-Personal Correlates, Income Generating Activities

\footnotetext{
${ }^{1}$ Department of Extension Education, Jawaharlal Nehru Agricultural University Jabalpur 482004 (MP), India

${ }^{2}$ Federal Inland Revenue Service, Lagos, Nigeria

*Corresponding author's email: chivicumunna@yahoo.com (V.C. Umunnakwe)
}

\section{Introduction}

The youth challenge is considered as the most critical of the 21st century's economic development challenge (Mahendra Dev and Venkatanarayana, 2011). These challenges seem to be more pronounced on rural youth when compared to their urban counterparts. For example, Bennell (2010) found that rural youth tend to be poorly educated especially in comparison to urban youth. Resolving these challenges is further threatened by limited information on rural youth's livelihoods. According to Waldie (2004), much information has not been collected on rural youth and their livelihoods in many countries despite the fact that the present day burning problems globally relates to them. Additionally, given the limited relevance of youth as a distinct and protracted transitional phase in most rural areas, they may have limited usefulness as a social category and this poses a serious problem resolving their numerous challenges especially developing major rural development policy initiatives around them.

About 84 per cent of the world's youth live in developing countries and India has the largest youth population in the world (United Nations, 2004). According to the 2001 Census in India, the total population of India was 1,028.61 million and nearly 40 per cent of the population was in the age group of 13 to 35 years. According to ADB (2008), India contributes about 33 percent of youth's population in the developing Asian countries. United Nations (2004) reported that approximately a quarter of the world's estimated youth population or 238 million youth were living in extreme poverty during the year 2000 and added that low-income countries and lowermiddle income countries, which together accounts for 80 per cent of the world's population 
of young people are highly concentrated in the regions of sub-Saharan Africa and South Asia.

Contrary to the prototype image of either depending purely on agricultural or nonagricultural activities, rural youth rely on many activities and income sources. They are engaged in a diverse range of productive activities in both agricultural and non-agricultural sectors. VargasLundius and Lanly (2007) stated that in developing countries agriculture provides the basis for a major share of employment, constitutes the main source of livelihood for a large portion of the population and added that reasonable proportion of rural youth are involved in agricultural production that include; crop production, animal rearing and rural farm wage labour. However, for any given youth, the low incomes, high risk and insufficient gains compared to the effort required make agriculture a very poor proposition (Sharma, 2007). In a related development, CTA (2010) found that decreasing involvement of youth in agriculture was because of low level of agricultural skills and limited access to financial resources. Consequently, rural youth are forced to look at alternative non-agricultural livelihood activities for their survival. Reardon et al. (2001) reported that in 1990s, rural non-farm activities accounted for 42 per cent of rural households' income in Africa, 40 per cent in Latin America and 32 per cent in Asia. They added that there is an increasing involvement of rural youth in rural non-farm activities like craft-work, trade, and employment in both unorganized as well as organized non-agricultural private sectors.

A framework for understanding youth must necessarily include both continuity and change and thus analyses of youth and youth livelihoods provides a useful entry point from which to explore and contribute some dynamic aspects to established models of sustainable livelihoods (Chisholm, 1990). A focus on youth is of particular relevance in providing a key entry point into the analysis of the ways in which new livelihoods are established (RYL, 2002). Recognizing some of the many different ways by which livelihoods are formed is crucial to understanding the mechanisms that enable some people to lift them out of poverty and the structural factors that may instead reproduce poverty. Aocording to RYL (2005), an analysis of youth livelihoods can support the necessary broadening of the concept of sustainability to allow capture the dynamics of intergenerational factors and their influence on the sustainability of new livelihoods.

According to Sheheli (2012), when different dimensions of the livelihood issue are considered, the incidence of income is the most important. Living standard of the rural poor would only be uplifted when they receive income from the economic activities (Ahmed et al., 2007; Ahmed, 2009). Ullah and Routray (2007) opined that income generating activities change the livelihood of the poor in terms of living condition, housing, nutrition, savings, dress, medical treatment, health, sanitation, liberalization and education. The study therefore aims at analyzing the sociopersonal characteristics of rural youth and their participation in livelihood activities as well as the relationships that exist between these characteristics and livelihood participation.

\section{Methodology}

\section{Description of the study area}

Jabalpur district is located in Madhya Pradesh, India. It is bounded by Damoh district in the northeast; Katni and Umaria districts in the northwest; Dindor and Mandla districts in the southeast and Narshimhapur district in the southwest. Jabalpur is located on $23^{\circ} 10^{\prime} \mathrm{N}$ latitude and $79^{\circ} 57^{\prime} \mathrm{E}$ longitude. According to the 2011 census, Jabalpur district has a population of $2,460,714$ people. The area of the district is $10,160 \mathrm{~km}^{2}$ while the administrative headquarters is located at Jabalpur city (Wikipedia, 2013).

\section{Sampling procedure and sample size}

Multi-stage random sampling was used to constitute the sample. Jabalpur block was excluded in the sampling due to unprecedented urbanization and two blocks namely Panagar and Patan were selected out of the remaining six blocks that were predominantly rural. Ten rural villages (five each from the two blocks selected) were delineated for the study. Twenty percent of the total households in the ten rural villages were selected and one youth from each household was interviewed bringing the sample size to two hundred and forty seven (247). 
Table 1. Villages and rural youth sampled in the study area

\begin{tabular}{clll}
\hline Sl.No. & Villages & Total households & No. of youth selected \\
\hline 1 & Belkhadu & 13 & 3 \\
2 & Padariya & 381 & 76 \\
3 & Pipariya & 87 & 17 \\
4 & Pondi & 67 & 13 \\
5 & Umaliya & 115 & 23 \\
6 & Benikheda & 223 & 45 \\
7 & Doni & 60 & 12 \\
8 & Luhari & 89 & 18 \\
9 & Nimi & 44 & 9 \\
10 & Timri & 157 & 31 \\
\hline & Total & 1236 & 247 \\
\hline
\end{tabular}

\section{Method of data collection}

Data were collected through interview schedule. According to Ogunlade and Adebayo (2009), direct face-to-face interview is the most commonly used data collection approach. Focus group discussion (FGD) was also used to elucidate information on livelihood activities of rural youth in the study area.

\section{Measurement of variables}

The dependent variable for the study which is participation in livelihood activities was operationalized as income generating activities and measured using a 3 point Likert type scale of full participation, partial participation and no participation $(2,1,0)$. Afterwards, the frequencies of full participation and partial participation were summed up to give total number of respondents who participated in different livelihood activities. Caste of respondents was measured by a selfanchored scale while other socio-personal characteristics like marital status, family occupation and family type were captured by self scoring. The exact class and level of highest educational attainment of respondents and their fathers were collected and categorized (illiterate $=1$; functional illiterate $=2$; primary school=3; middle school $=4$; high school $=5$ and graduate and above $=5$ ). In addition, the exact number of total members of respondents' family was collected and classified (small family $=1$; medium family $=2$ and large family $=3$ ).

\section{Analysis of data}

Data were analyzed with statistical package for social science (SPSS). Descriptive statistics used were frequency counts and percentages while inferential statistics employed was Pearson product moment correlation (PPMC).

\section{Results and Discussion}

Table 2 shows that majority of the rural youth were from other backward caste (66\%), married $(72.10 \%)$ and from families that were selfemployed in agriculture (59.50\%). More than half of rural youth and their fathers were educated up to high school and above and primary school and above respectively. Greater proportions of the rural youth belonged to joint family as well as family with medium member size. Similar finding was reported by Jayaraman (2013) who stated that the highest proportion of youth was from other backward caste in rural areas. NSSO (2011) found that highest proportion of rural youth in India were married and belonged to households that were self-employed in agriculture. Traditionally, the Indian population is characterized by universal marriage and an early age at marriage. However, sizeable number of rural youth's fathers had formal education; however, a significant proportion were illiterate. It is quite striking that none of the rural youth was an illiterate signifying that even the illiterate fathers in recent time are trying to let their wards to be educated. Strong attachment to family of birth coupled with unalloyed affinity towards communality could be the possible explanation for prevalence of joint family. Singh (2008) found an overwhelming prevalence of positive attitude toward joint and extended families among people of Indian origin. 
Table 2. Frequency distribution and categorization of respondents' socio-personal characteristics

\begin{tabular}{|c|c|c|}
\hline Variables & Frequencies & Percentages \\
\hline \multicolumn{3}{|l|}{ Caste (SD $=0.584)$} \\
\hline Scheduled caste and tribe & 44 & 17.80 \\
\hline Other backward caste & 163 & 66.00 \\
\hline Forward/general caste & 40 & 16.20 \\
\hline Total & 247 & 100.00 \\
\hline \multicolumn{3}{|l|}{ Marital status (SD =0.899) } \\
\hline Unmarried & 69 & 27.90 \\
\hline Married & 178 & 72.10 \\
\hline Total & 247 & 100.00 \\
\hline \multicolumn{3}{|l|}{ Family occupation (SD =1.087) } \\
\hline Farming & 147 & 59.50 \\
\hline Trading & 40 & 16.20 \\
\hline Civil service & 28 & 11.30 \\
\hline Wage labour & 32 & 13.00 \\
\hline Total & 247 & 100.00 \\
\hline \multicolumn{3}{|c|}{ Fathers' educational attainment ( Mean $=5.75, \mathrm{SD}=5.024$ ) } \\
\hline Illiterate & 48 & 19.40 \\
\hline Functionally literate & 35 & 14.20 \\
\hline Primary school & 44 & 17.80 \\
\hline Middle school & 48 & 19.40 \\
\hline High school above & 72 & 29.10 \\
\hline Total & 247 & 100.00 \\
\hline \multicolumn{3}{|c|}{ Respondents' educational qualification ( Mean $=10.33, \mathrm{SD}=4.128$ ) } \\
\hline Illiterate & 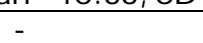 & - \\
\hline Functionally literate & 12 & 4.90 \\
\hline Primary school & 28 & 11.30 \\
\hline Middle school & 44 & 17.80 \\
\hline High school & 105 & 42.50 \\
\hline Graduated and above & 58 & 23.50 \\
\hline Total & 247 & 100.00 \\
\hline \multicolumn{3}{|l|}{ Family type $(\mathrm{SD}=4.189)$} \\
\hline Individual & 104 & 42.10 \\
\hline Joint family & 143 & 57.90 \\
\hline Total & 247 & 100.00 \\
\hline \multicolumn{3}{|l|}{ Family size $($ Mean $=6.99, \mathrm{SD}=3.800)$} \\
\hline Small family (1- 3 members) & 20 & 8.10 \\
\hline Medium family ( 4 - 6 members) & 125 & 50.60 \\
\hline Large family(7 members\& above) & 102 & 41.30 \\
\hline Total & 247 & 100.00 \\
\hline
\end{tabular}

Table 3. Frequency distribution of respondents' participation in livelihood activities

\begin{tabular}{clll}
\hline Sl.No. Livelihood activities & Frequency & Percentage \\
\hline 1 & Cereal production & 187 & 75.71 \\
2 & Pulse production & 139 & 56.28 \\
3 & Petty trading & 132 & 53.44 \\
4 & Vegetable production & 114 & 46.15 \\
5 & Construction work & 88 & 35.63 \\
6 & Hired labour & 80 & 32.39 \\
7 & Milk production & 79 & 31.98 \\
8 & Oil seed production & 72 & 29.15 \\
9 & Teaching/ civil service & 68 & 27.53 \\
10 & Transportation & 64 & 25.91 \\
11 & Fruit production & 60 & 24.29 \\
12 & Rental services & 60 & 24.29 \\
13 & Cash crop production & 60 & 24.29 \\
14 & Local party agent/ council member & 46 & 18.62 \\
15 & Goat rearing & 36 & 14.58 \\
16 & Tailoring & 32 & 12.96 \\
17 & Fish farming & 30 & 12.15 \\
18 & Raising plants for fruit production & 30 & 12.15 \\
19 & Selling of traditional medicine & 28 & 11.34 \\
20 & Blacksmith & 20 & 8.10 \\
\hline
\end{tabular}


Table 3 reveals that majority of rural youth were involved in cereal production (75.71\%) and pulse production (56.28\%). Prominent cereal crops cultivated in the study area are wheat, rice, maize and sorghum while major pulse crops include pigeon pea, chickpea, green gram, and black gram. Other crop productions that rural youth participated include vegetable production (tomato, onion, cauliflower, potato, cabbage, chilli, pepper and cucumber); oil seed production (soya bean and mustard seed) and fruit production (mango, papaya and guava). Similar findings were reported by Oladeji (2007); Nandini and Kiresur (2013) that crop production is the most participated agricultural income generating activities among rural dwellers. Significant proportions of rural youth were involved in milk production. Domestic and commercial demand for fresh whole milk undoubtedly prompted the keeping of buffaloes and cows for the production of milk. Cash crop production is another agricultural livelihood activity that is worth mentioning here. Cash crops are produced primarily for their commercial value rather than for use by the grower. Though pulses and oilseeds could be considered as cash crop when they are produced in large quantities for commercial purpose however, sugarcane, tendu leaves and medicinal crops were particularly identified as cash crops in this study.
Specifically, the rising habits of beedi smoking and sweet intake are the driving forces behind the production of tendu leaves and sugarcane as the case may be. Tendu leaves make excellent wrappers and the success of the beedi industry is due in part to this leaf.

The most participated non-farm livelihood activity among rural youth was petty trading (53.44\%). Similar finding was reported by Oladeji (2007) and Oyesola (2007). The possible explanation could be low skill and low capital requirements associated with participation in petty trade. Significant numbers of rural youth were involved in hired labour, construction work and transportation. Daily wages vis-à-vis urgent and pressing individual/family needs could be responsible for the involvement of rural youth in hired labour especially the skill deficient ones.

Okoye (1995); CPD (2004); Oladeji (2007); Sheheli (2012) and Ovwigho (2014) affirm that even though farming is the predominant activity in most rural areas, rural dwellers usually engage in non-farm income generating activities. The findings support the view of Bennell (2010) who opined that rural youth are engaged in a diverse range of productive activities both agricultural and non-agricultural which make up their livelihood strategies.

Table 4. Relationship between socio-personal characteristics of rural youth and their involvement in livelihood activities

\begin{tabular}{cll}
\hline Sl. No. & Socio-personal attributes of rural youth & PPMC values \\
\hline $\mathrm{X}_{1}$ & Caste & $0.105^{\mathrm{NS}}$ \\
$\mathrm{X}_{2}$ & Marital status & $0.175^{* *}$ \\
$\mathrm{X}_{3}$ & Family occupation & $-0.045^{\mathrm{NS}}$ \\
$\mathrm{X}_{4}$ & Fathers' education & $0.148^{*}$ \\
$\mathrm{X}_{5}$ & Respondents' education & $-0.002^{\mathrm{NS}}$ \\
$\mathrm{X}_{6}$ & Family type & $0.179^{* *}$ \\
$\mathrm{X}_{7}$ & Family size & $0.178^{* *}$ \\
\hline
\end{tabular}

NS $=$ Not significant

* Significant at 0.05 level ( 2 - tailed)

** Significant at 0.01level ( 2 - tailed)

Caste: the study found that there was no significant relationship between caste of rural youth and their involvement in livelihood activities. This implies that rural youth participate evenly in various livelihood activities irrespective of their caste. It is commonsensical therefore to say that living and survival would be difficult for independent rural youth who do not participate in livelihood activities. Traditionally, a large proportion of rural youth obtain their livelihoods either through supporting their family enterprises or working on their own account in agriculture, trade-related enterprises and craft industries, and in many cases contribute to family income or support themselves entirely while still in full-time education (Porter et al., 2007). In a related finding, Saha and Bahal (2010) reported that caste had no significant relationship with farmers' degree of livelihood diversification.

Marital status: marital status was found to be positively related to participation in livelihood activities among rural youth. The import of this finding is that married rural youth are more involved in livelihood activities than unmarried ones. The explanation is not farfetched as married rural youth are saddled with more responsibilities, which make them to participate 
more in livelihood activities to meet up with their responsibilities.

Family occupation: the results of the study showed that no significant relationship exists between family occupation of rural youth and their involvement in livelihood activities. This means that rural youth from families with different occupations are involved in livelihood activities.

Fathers' education: the relationship between educational attainment of rural youth's fathers and rural youth involvement in livelihood activities was found to be positive. The implication of this is that rural youth whose fathers are more educated tend to be more guided in the livelihood choices they make. This invariably increases their ability to make good livelihood choices as well as participation in livelihood activities and thus enhances their transition into productive citizens and providers of their families.

Respondents' education: Rural youth's educational level had no significant relationship with their involvement in livelihood activities. Implicitly, rural youth's participation in livelihood activities does not in any way depend on their level of education. Both highly educated and less educated one are involved in livelihood activities. In a related finding, Sunanda et al. (2014) reported that education was not related to sustainable livelihood. Therefore, participation in livelihood activities and the sustainability of the livelihood activities are not dependent on educational attainment.

Family type: family type of rural youth had a positive relationship with their involvement in livelihood activities. This implies that rural youth from joint family type are more involved in income generating activities. Usually, joint families have large family size and more members than nuclear families. As a result, the responsibility of family upkeep and welfare is shared among independent family members who participate in livelihood activities to live up to their responsibilities.

Family size: the relationship between family size of rural youth and their involvement in livelihood was found to be positive. The finding indicates that rural youth from larger sized families are likely to participate more in livelihood activities than those from smaller sized families. The more reasonable interpretation of the finding is that the larger the family size, the more difficult it becomes for household heads to provide for the needs of the entire members of the family. This scenario undoubtedly prompts young members of these households to participate in livelihood activities. Binkadakatti (2013) concluded that family size has positive and significant relationship with livelihood security of rehabilitant farmers while Ovwigho (2014) found that household size has positive association with income generating activities of farmers.

Table 5: Inter-correlation of socio-personal characteristics

\begin{tabular}{|c|c|c|c|c|c|c|c|c|}
\hline Sl. No. & Socio-personal character & & $\mathrm{X}_{2}$ & $\mathrm{X}_{3}$ & $\mathrm{X}_{4}$ & $\mathrm{X}_{5}$ & $\mathrm{X}_{6}$ & $\mathrm{X}_{7}$ \\
\hline $\mathrm{X}_{1}$ & Caste & 1 & & & & & & \\
\hline $\mathrm{X}_{2}$ & Marital status & $*_{-0} 0.141$ & 1 & & & & & \\
\hline $\mathrm{X}_{3}$ & Family occupation & -0.063 & 0.053 & 1 & & & & \\
\hline $\mathrm{X}_{4}$ & Father's education & $* * 0.254$ & $* *_{-} 0.251$ & $* * 0.360$ & 1 & & & \\
\hline $\mathrm{X}_{5}$ & Respondents' education & $* * 0.229$ & $* * 0.184$ & -0.050 & $* * 0.287$ & 1 & & \\
\hline $\mathrm{X}_{6}$ & Family type & 0.033 & $* * 0.385$ & -0.084 & -0.043 & -0.050 & 1 & \\
\hline $\mathrm{X}_{7}$ & Family size & $*_{-} 0.154$ & 0.015 & -0.076 & $* *-0.298$ & **-0.242 & $* * 0.577$ & 1 \\
\hline
\end{tabular}

* Significant at 0.05 level (2 - tailed)

** Significant at 0.01 level (2 - tailed)

Inter-correlation of socio-personal characteristics revealed that caste of the respondents was negatively related to their marital status. Implicitly, rural youth from lower castes like scheduled caste/ tribe category are likely to marry earlier than rural youth from the higher castes like general category. The reason could be that rural youth from higher castes tend to have higher educational attainment which make them to marry after their education and thereby prolongs their time of marriage. This is further corroborated as shown by the positive relationship between caste and respondents' educational qualification. There was a positive

relationship between fathers' education and family occupation. This means that as the fathers' education increases there is a shift away from farming probably towards occupation that requires basic literacy and numeracy that can be acquired from formal educational settings. It was also found that respondents' educational attainment was positively related to their fathers' educational qualification implying that respondents whose fathers have higher educational qualification tend to have higher educational attainment as well. This is quite in line with a priori expectation. Also, it was found that respondents' educational attainment had 
negative relationship with family size. As the respondents' education increased, family size decreased. The explanation could be that educated rural youth tend to have smaller family size probably because of their awareness of family planning as well as governmental restriction on the number children a government employee should give birth to.

\section{Conclusion and Recommendations}

It is evident from the study that rural youth in Jabalpur district of Madhya Pradesh, India were involved in a number of livelihood activities including agricultural and nonfarm income generating activities. The study established relationship between participation in livelihood activities and socio-personal characteristics of rural youth. Variables such as marital status, fathers' educational attainment, family size and family type were positively related to participation in livelihood activities. The inter correlation among socio-personal characteristics revealed that caste had significant positive and negative relationship with rural youth's educational level and marital status respectively. While educational level of the respondents had significant positive and negative relationship with their fathers' educational attainment and family size respectively. The study therefore concludes that rural youth participate in both agricultural and non-agricultural livelihood activities and their socio-personal characteristics are significantly related to their participation in these activities. Due to significant participation of rural youth in agricultural livelihood activities especially cereal and pulse production, the study recommends that youth extension delivery, which is presently, subsumed in general extension programmes should be delineated to cater for their specific needs in agricultural production. Rural development policy makers should consider the socio-personal variables of present study when undertaking programmes targeted at enhancing rural youth's livelihoods.

\section{References}

ADB. 2008. Asian Development Outlook 2008: Asian Workers. Asian Development Bank, Hongkong. p. 41

Ahmed, N. 2009. The Sustainable Livelihoods Approach to the Development of Fish Farming in Rural Bangladesh. J. Int. Farm Manage. 4(4): 1-18.

Ahmed, N., Wahab, M.A. and Thilsted, S.H. 2007. Integrated Aquaculture-Agriculture Systems in Bangladesh: Potential for Sustainable Livelihoods and Nutritional Security of the Rural Poor. Aqua. Asia 12(1): 14-22.
Bennell, P. 2010. Investing in the Future, Creating Opportunities for Young Rural People. Rome, IFAD. p. 5.

Binkadakatti, J. 2013. Analysis of Livelihood Security of Rehabilitant Farmers. Karnatak J. Agric. Sc. 26(4): 574.

Chisholm, L. 1990. A Sharper Lens or a New Camera? Youth Research, Young People and Social Change in Britain. In: Childhood, Youth and Social Change. A Comparative Perspective, (Eds.): Chisholm, L., Buchner, P., Kruger, H. and Brown, H. Falmer, London, pp. 33-57.

CPD. 2004. Nature and Impact of Women's Participation in Economic Activities in Rural Bangladesh. Centre for Policy Dialogue (CPD) and International Rice Research Institute (IRRI) Policy Brief 7. http:// www.cpdbangladesh.org/

CTA. 2010. A Reader: Briefing No 19-Youth and Rural Development in ACP Countries. Brussels. p. 5.

J ayaraman, A. 2013. A demographic overview. In: State of the Urban Youth, India 2012, Employment, Livelihood, Skills. (Eds.): Prakash, P. UNHABITAT and IRIS. pp. 7-14.

Mahendra Dev, S. and Venkatanarayana, M. 2011. Youth Employment and Unemployment in India. Indra Gandhi Institute of Development Research Publication. Access Date 02.06.2014. http:// www.igidr.ac.in/pdf/ publication/ wp2011-009.pdf

Nandini, S. and Kiresur, V. R. 2013. Engendering Rural Livelihoods in Karnataka - A Socioeconomic Assessment. Agril. Economics Res. Rev. 26(2): 97-107.

NSSO. 2011. Key Indicators of Employment and Unemployment in India, NSS 66 $6^{\text {th }}$ Round July 2009 - June 2010. National Sample Survey Office, Ministry of Statistics and Programme Implementation, Government of India.

Ogunlade, I. and Adebayo, S.A. 2009. Socioeconomic Status of Women in Rural Poultry Production in Selected Areas of Kwara State Nigeria. Int. J. Poultry Sci. 8: 55-59.

Okoye, C.U. 1995. The Rural Economy and Community Banking in Nigeria. In: Rural Development in Nigeria: Concepts, Processes and Prospects. (Eds.): Eboh, E. C., Okoye, C. U. and D Ayichi D. Auto-Century Publishing Company, Enugu. pp. 200-215.

Oladeji, J.O. 2007. Effect of Land Degradation on Income Generating Activities of Farmers in Imo State, Nigeria. J. Econ. Rural Dev. 16(1): 93-106.

Ovwigho, B.O. 2014. Factors Influencing Involvement in Nonfarm Income Generating Activities among Local Farmers: The Case of Ughelli South Local Government Area of 
Delta State, Nigeria. Sustainable Agric. Res. 3(1): 76-84.

Oyesola, O.B. 2007. Rural Dwellers Perception on Effect of Infrastructural Facilities on Livelihood Activities in Akinyele Local Government Area of Oyo State, Nigeria. J.Econ.Rural Dev. 16(1): 83-92.

Porter, G., Blaufuss, K. and Owusu, A.F. 2007. Youth, Mobility and Rural Livelihood in SubSaharan Africa: Perspectives from Ghana and Nigeria. Africa Insight 37(3): 420 - 431.

Reardon, T., Berdegue, J. and Escober, G. 2001. Rural Nonfarm Employement and Incomes in Latin America: Overview and Policy Implications, World Dev. 29(3): 411-425.

RYL. 2002. A Report on a Scoping Mission to Uganda, Kenya and Tanzania for NRSP Programme Development 111: University of Reading, ITAD. p. 5.

RYL. 2005. Enhancing Capacity for Enterprise and Innovation: An Investigation of the Livelihood Assets and Strategies of Rural Youth in East Africa. Natural Resources Systems Programme R 8211: The University of Reading, DFID. p. 4.

Saha, B. and Bahal, R. 2010. Livelihood Diversification Pursued by Farmers in West Bengal. Indian Res. J. Ext. Edu. 10(2): 1-9.

Sharma, A. 2007. The Changing Agricultural Demography of India: Evidence from a Rural Youth Perception Survey. Int. J. Rural Manage. 3(1): 27-41.

Sheheli, S. 2012. Improving Livelihood of Rural Women through Income Generating
Activities in Bangladesh. PhD Dissertation, Humboldt University, Berlin Germany. p. 3.

Singh, A. 2008. A Critical Evaluation of Attitudes towards Nuclear, J oint and Extended Family Structure among People of Indian Origin in Durban, South Africa. J. Comparative Family Studies 39(4): 453-470.

Sunanda, T., Singh, M.K., Ram, D. and Chaudhary, K.P. 2014. Assessment of the Sustainable Livelihoods of Loktak Lake Islanders in Bishnupur District of Manipur. Indian Res. J . Ext. Edu. 14(3): 70-74.

Ullah, A.K.M.A. and Routray, J.K. 2007. Rural Poverty Alleviation through NGO Interventions in Bangladesh: How Far is the Achievement? Int. J. Soc. Econ. 34(4): 237 248.

United Nations. 2004. World Youth Report 2003. The Global Situation of Young People. Newyork. pp. 2-91.

Vergas-Lundius, R. and Lanly, G. 2007. Migration and Rural Employment. Paper Prepared for the Round Table Organised by the Policy Division During the Thirtieth Session of the Governing Council of IFAD. pp. $12-24$.

Waldie, K. 2004. Youth and Rural Livelihoods. Low Exte. Input Sust. Agric. 20: 6-8.

Wikipedia. 2013. Jabalpur. Retrieved from http:// en.wikipedia.org/ wiki/jabalpur_distr ict 